\title{
An Immunohistochemical Study of the Significance of a New 31.5-kD Ouabain Receptor Protein Isolated from Cat Cardiac Muscle
}

\author{
Masako Fujino ${ }^{1}$ and Sumiko Fujino ${ }^{2}$ \\ 'Department of Pharmacology, Sapporo Medical University, Minami I Nishi 17, Chuo-ku, Sapporo 060, Japan \\ ${ }^{2}$ Pharmacology Division of Sapporo Research Institute for Muscle Sciences, 1-1-6, Izumicho, Makomanai, Minami-ku, Sapporo 005, Japan
}

Received July 20, 1994 Accepted November 11, 1994

\begin{abstract}
A new 31.5-kD ouabain receptor protein (NORP), which is independent of $\mathrm{Na}^{+}-\mathrm{K}^{+}$ATPase, was recently isolated selectively from transverse tubule membrane-junctional sarcoplasmic reticulum (TTMJSR) complexes of cat cardiac muscle. We investigated the role of this NORP in cardiac function with special reference to the positive inotropic effect (PIE) of ouabain, preparing and using a monoclonal antibody (MoAB, immunoglobulin) raised against the receptor protein. Electrically stimulated papillary muscles were immersed in a Tyrode solution containing the anti-NORP MoAB $(40 \mu \mathrm{M})$, of which the binding potency was high enough for immunological use, for $60 \mathrm{~min}$ and then washed out. Thirty minutes after removal of the MoAB, both twitch and K-contracture were still inhibited, but both resting and action potentials and caffeine-induced contracture were unchanged, indicating that NORP plays a key role in excitation (E)-contraction (C) coupling. The intracellular localization of the protein was investigated by immunohistochemical electron microscopy, and the protein was shown to be located on the TTM, the location being probably its external surface and opposite to feet which occupy the TTM-JSR gap. These results indicate that E-C coupling of cardiac muscle cells is mediated through NORP and that ouabain-PIE occurs through the influence of ouabain on NORP in the E-C coupling process.
\end{abstract}

Keywords: New ouabain receptor protein, Monoclonal antibody, Excitation-contraction Coupling, Immunoelectron microscopy, Cardiac muscle (cat)

There have been many studies on the mechanism of the positive inotropic effect (PIE) of cardiac glycosides on cardiac muscle. They demonstrated that glycosides bind to a high affinity site on the $\mathrm{Na}^{-}-\mathrm{K}^{+}$ATPase, but the detailed mechanism is still a matter of speculation $(1-14)$. However, we recently solubilized a novel $31.5-\mathrm{kD}$ ouabain receptor protein (NORP) from cardiac muscle that is independent of the $\mathrm{Na}^{+}-\mathrm{K}^{+}$ATPase of cardiac muscles (15). This protein is extractable almost selectively from the transverse tubule membrane-junctional sarcoplasmic reticulum (TTM-JSR) system, which is regarded as a regulator of mechanical contraction or force-generation in muscle cells $(16-19)$; and as shown by ${ }^{3} \mathrm{H}$ ouabain photolabeling, it is probably responsible for ouabain potentiation (15).

Although the mechanism of coupling of the electrical events (E) at the TTM with the intracellular Ca-release indispensable for contraction (C) is still not sufficiently understood $(17,18,20-25)$, our previous studies $(26-36)$ have suggested that ouabain potentiation is produced by the action of ouabain on the E-C coupling process in the cardiac muscle.

In the present study, therefore, we examined the role of NORP in cardiac function with special reference to the PIE of ouabain; i.e., the physiological role and intracellular localization of NORP were investigated with a monoclonal antibody (MoAB) raised against the protein. A preliminary report of some of these results was published previously as an abstract (36).

\section{MATERIALS AND METHODS}

\section{Recording of developed tension}

Papillary muscles (about $0.5 \mathrm{~mm}$ in diameter and about $3-5 \mathrm{~mm}$ in length) were isolated from the right cardiac ventricle of anesthetized $(30 \mathrm{mg} / \mathrm{kg}$ sodium pentobarbital, i.p.) male kittens ( 1.5 to $2.3 \mathrm{~kg}$ ). These were attached to a mechanoelectric transducer system (TB 1567; Nihon Kohden, Tokyo) at rest length (115\% of the equilibrium length; resting tension, i.e., initial load, 
about $300 \mathrm{mg}$ ) and immersed in $200 \mu \mathrm{l}$ normal Tyrode solution containing $145 \mathrm{mM} \mathrm{NaCl}, 4.7 \mathrm{mM} \mathrm{KCl}, 1.3 \mathrm{mM}$ $\mathrm{CaCl}_{2}, 0.4 \mathrm{mM} \mathrm{NaH} \mathrm{PO}_{4}, 1.0 \mathrm{mM} \mathrm{MgCl}_{2}, 10 \mathrm{mM}$ glucose and $5.0 \mathrm{mM} \mathrm{NaHCO}$ (pH 7.0). Bathing solutions were oxygenated with $95 \% \mathrm{O}_{2}$ and $5 \% \mathrm{CO}_{2}$. Twitch and contracture tensions were measured isometrically. All experiments were performed at about $23^{\circ} \mathrm{C}$.

When twitch tension $(0.1 \mathrm{~Hz})$ attained equilibrium, the bathing solution was replaced with fresh normal Tyrode solution. Then anti-NORP MoAB was applied for 60 min, after which time it was removed. Anti-NORP MoAB was used at a concentration of $10 \mu \mathrm{g} / \mathrm{ml}$; and in the control cases, nonimmune immunoglobulin was applied (see the subsection after next). Stimuli consisted of rectangular pulses, $3 \mathrm{msec}$ in duration at twice the threshold intensity delivered by an electrical stimulator (SS-101J, Nihon Kohden). To evoke contracture, the normal Tyrode solution was replaced by either K-Tyrode solution (145 $\mathrm{mM} \mathrm{K}$ instead of $\mathrm{Na}$ ) or K-Tyrode solution containing 50 $\mathrm{mM}$ caffeine.

\section{Isolation of TTM-JSR complexes and solubilization and purification of NORP}

Isolation of TTM-JSR complexes and solubilization and purification of NORP, the $31.5-\mathrm{kD}$ protein, were performed according to the previously described methods $(15,37)$ except for the additional use of wheat germ agglutinin (WGA) affinity chromatography to remove all the dihydropyridine (DHP) receptor protein and its subunits. WGA affinity chromatography was done according to Curtis and Catterall (38). The $31.5-\mathrm{kD}$ protein in the present study was one of the concanavalin A (Con A)-sensitive proteins in the WGA-void fraction obtained by partitioning of a 3-(3-cholamidopropyl)dimethyl-ammonio1-propanesulfonate (CHAPS) extract of cat cardiac TTMJSR complexes. The $31.5-\mathrm{kD}$ protein was purified as follows: A band with molecular weight of $31.5 \mathrm{kD}$ ( $a$ in B-2 of Fig. 1) was cut out of the gel, and this slice was crushed in elution buffer ( $\mathrm{pH} 5.3$ ) comprising $0.1 \%$ SDS, $0.1 \mathrm{mM}$ EDTA, $5 \mathrm{mM}$ dithiothreitol, $150 \mathrm{mM} \mathrm{NaCl}$ and buffering reagents (100 mM citric acid and $\left.200 \mathrm{mM} \mathrm{Na}_{2} \mathrm{HPO}_{4}\right)(15)$.

\section{Preparation of the anti-NORP MoAB}

The anti-NORP MoAB (No. CH9201) was prepared as an immunoglobulin by the previously described method (37) except for the use of cat cardiac NORP instead of frog skeletal $31.5-\mathrm{kD}$ protein (electrometrin) as the antigen. A 5- to 6-week-old female $\mathrm{BALB} / \mathrm{c}$ mouse received an intraperitoneal injection of the Con A-sensitive proteins (100 $\mu \mathrm{g}$ of protein) from cat cardiac muscle TTMJSR in Freund complete adjuvant. Then the immunization was repeated twice at 2-week intervals with $50 \mu \mathrm{g}$ of the proteins in the adjuvant. Two days after the last im- munization, the mouse was sacrificed. Spleen cells were fused with myeloma cells (63-Ag8-6.5.3). At 10-14 days after the fusion, hybridomas with the ability to secrete AB against the NORP ( $31.5 \mathrm{kD})$ were selected and cloned by the limiting dilution technique and ELISA. Ascites fluids were produced. The fluids were centrifuged at $15,000 \times \mathrm{g}$ for $15 \mathrm{~min}$, and the immunoglobulin fraction was precipitated in ammonium sulfate $\left(\mathrm{pH} \mathrm{7.4)}\right.$ at $4^{\circ} \mathrm{C}$ for $2 \mathrm{hr}$. The precipitate was dialyzed against $10 \mathrm{mM}$ phosphate buffer containing $110 \mathrm{mM} \mathrm{NaCl}$ (pH 7.2). After the dialysis, the immunoglobulin fraction was purified by protein A-affinity chromatography, freeze-dried and stored at $-90^{\circ} \mathrm{C}$.

\section{Binding potency of $M o A B$}

The binding potency of the prepared MoAB protein was determined with the ELISA method. In the ELISA method, the minimum MoAB concentration required for saturation of NORP was $5.0 \mu \mathrm{g} / \mathrm{ml}$, showing that the isolated MoAB globulin is of sufficiently high potency for immunological applications. In the experiments, MoAB was used at a protein concentration of $10 \mu \mathrm{g} / \mathrm{ml}$ (about 40 $\mathrm{nM}$ ), which is 2-fold higher than this minimum concentration. In the case of the control, nonimmune immunoglobulin $(10 \mu \mathrm{g}$ protein $/ \mathrm{ml})$ was used and applied. This protein was a mixture of immuno-inert preparations, which could be obtained from the procedure to prepare anti-NORP MoAB and goat anti-rabbit immunoglobulin.

\section{Western blot analysis}

After SDS-PAGE (4-20\% gradient gel (39)) of the purified 31.5 -kD protein from band in B-2 of Fig, 1, the protein band was transferred onto a nitrocellulose membrane (40). The membrane strip was incubated in incubation buffer containing MoAB $(10 \mu \mathrm{g} / \mathrm{ml})$ and then treated with an ABC Kit (avidin-biotin system; Vector Laboratories, Burlingame, CA, USA) according to the routine method for the nitrocellulose procedure. Diaminobenzidine was used as the color reagent for developing the immunoblot ( $a$ in C-2 of Fig. 1) as previously reported (37).

\section{Immunohistochemical electron microscopy}

Electron microscopy was performed by routine procedures. Either immunogold (diameter of gold particles: $5 \mathrm{~nm}$ ) or the $\mathrm{ABC}$ kit was used for immunohistochemical staining. The set-up for the first half (i.e., binding of antiNORP MoAB to living papillary cells) of the procedure was the same as that described for tension recording (see B of Fig. 2). That for the latter half (i.e., immunohistochemical procedure) was as follows:

1) Immunogold method: Thirty minutes after replacing the MoAB Tyrode solution with normal Tyrode solution (i.e., at a time-point just before K-contracture in $\mathrm{B}$ of 
Fig. 2), the muscle was transferred into another bath for immunohistochemical treatment for electron microscopy and held at rest length (115\% of the equilibrium length) in a phosphate solution ( $\mathrm{pH}$ 7.2). After rinsing for $5 \mathrm{~min}$, the muscle was immersed in the phosphate buffer solution (pH 7.2) containing anti-mouse immunogold solution ( $50 \mu \mathrm{l}$ in $200 \mu \mathrm{l}$ of bathing solution) for $30 \mathrm{~min}$ and then rinsed twice in the phosphate buffer solution without immunogold for $30 \mathrm{~min}$ each time. After rinsing, the tissue was fixed in $100 \mathrm{mM}$ sodium cacodylate buffer solution (pH 7.2) containing $1 \%$ glutaraldehyde and $5 \mathrm{mM} \mathrm{CaCl}_{2}$ at room temperature for $10 \mathrm{~min}$. The bathing solution was then replaced with a solution of the same composition, except containing $2.5 \%$ instead of $1 \%$ glutaraldehyde, at $4{ }^{\circ} \mathrm{C}$ overnight. After this fixation step, tissues were rinsed three times in a solution composed of $10 \%$ sucrose and $0.1 \mathrm{M}$ sodium cacodylate buffer, $\mathrm{pH} 7.2$, at room temperature for $30 \mathrm{~min}$ each time. The muscle was then post-fixed in $1 \%$ osmic acid solution for $3 \mathrm{hr}$ at $0^{\circ} \mathrm{C}$. Tissues were embedded in epon 812 and ultrathin (white or silver white) sections were cut with a diamond knife. Sections with (Fig. 5) or without (Fig. 6) routine double staining (usually, each $8 \mathrm{~min}$ ) with uranyl acetate and lead citrate were examined by electron microscopy (electron microscope, Hitachi 500 or Nihon Denshi 1200, Tokyo).

2) $A B C$ method: For $A B C$ staining, a mouse $A B C$ kit was used instead of immunogold. For detection of peroxidase, diaminobenzidine was used. After routine $A B C$ staining according to the manufacturer's instructions, the muscle was rinsed three times with the phosphate buffer solution ( $\mathrm{pH} 7.2)$ for 30 min each time and fixed in $2 \%$ osmic acid in the phosphate buffer solution for $30 \mathrm{~min}$ at room temperature. Segmented muscle preparations were then dehydrated through a graded ethanol series and embedded in Epon 812. Ultrathin (white or silver white) sections were examined by electron microscopy without dou-

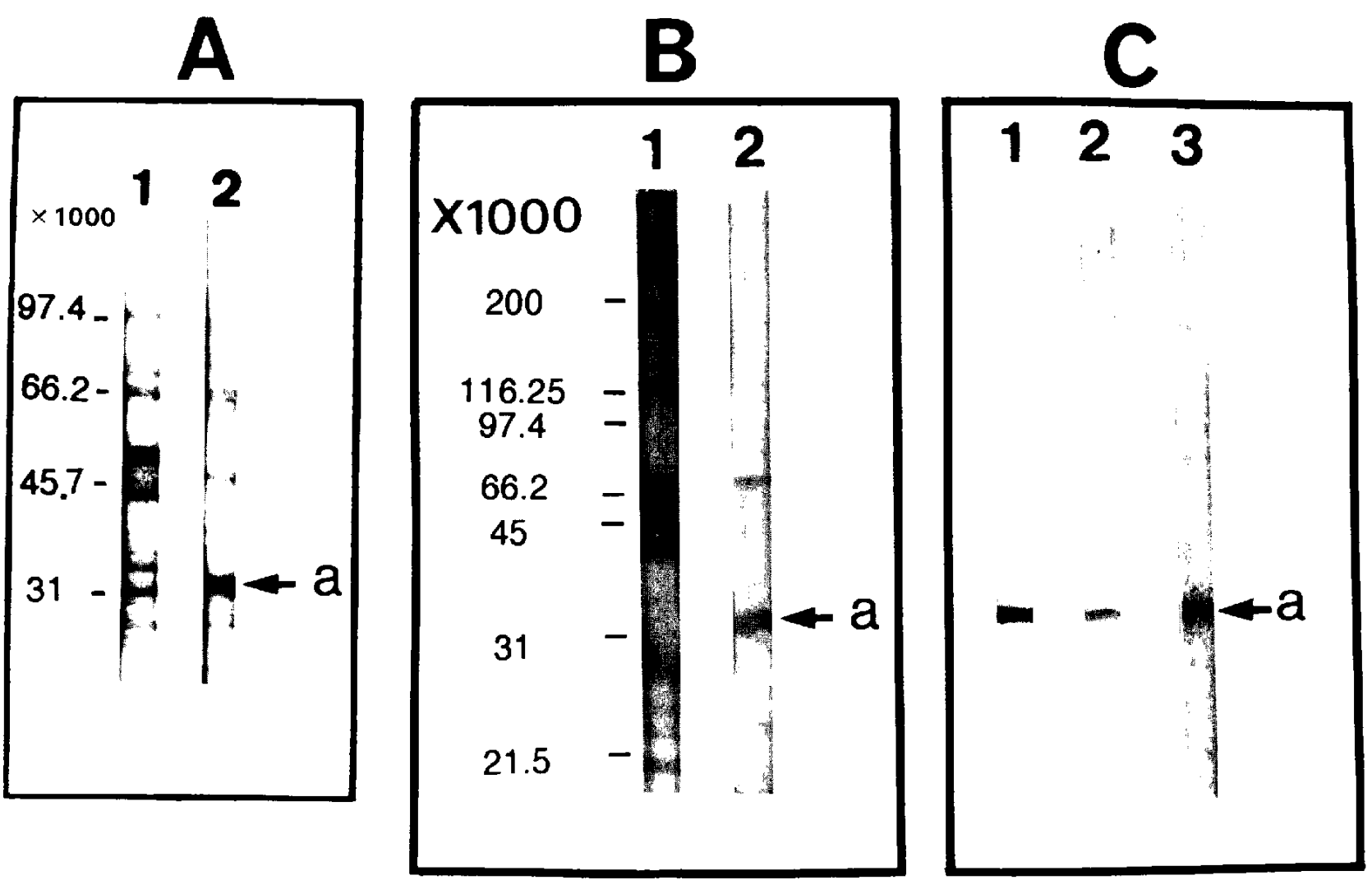

Fig. 1. Characteristics of the new oubain receptor protein isolated from cat cardiac ventricle and specificity of the MoAB raised against it. A-1: SDS-PAGE (12\% gel) profile (Coomassie brilliant blue (CBB)-staining) of proteins from TTM-JSR complexes. A-2: SDS-PAGE profile (CBB-staining) of proteins isolated by Con A affinity chromatography from TTM-JSR complexes. B-1: SDS-PAGE (4-12\% gel) profile (CBB-staining) of proteins isolated by WGA affinity chromatography from TTM-JSR complexes. B-2: SDS-PAGE profile of proteins (CBB-staining) isolated by Con A affinity chromatography of the WGA-void fraction from TTM-JSR complexes. C-1: SDS-PAGE profile (the longitudinal one third of the strip is shown) of the purified $31.5-\mathrm{kD}$ proteins $(4 / 2 \mathrm{~g} / 20 / 1)$ from band $a$ in B-2. C-2 and C-3: Proteins blotted onto a nitrocellulose membrane from the rest (longitudinal two third) of the strip in $\mathrm{C}-1$; the longitudinal one half of the membrane is shown, respectively. $\mathrm{C}-1$, stained with silver; C-2, Western blot developed by enzyme immunostaining (ABC kit) after MoAB treatment; C-3, autoradiogram obtained by incubation of the membrane with ${ }^{3} \mathrm{H}$-ouabain. See text for further explanations. 
ble staining.

Electron micrographs (Figs. 5, 6 and 7) were obtained from surface areas of the each papillary muscle.

\section{${ }^{3} H$-Ouabain binding to NORP and autoradiography}

Con A-sensitive proteins from the WGA-void fraction of TTM-JSR complexes were separated by SDS-PAGE and transferred onto a nitrocellulose membrane. The membrane was incubated with $0.5 \mu \mathrm{M}{ }^{3} \mathrm{H}$-ouabain (S.A., 1 $\mathrm{mCi} / \mathrm{ml}$ ) for $30 \mathrm{~min}$ at $23^{\circ} \mathrm{C}$ in the same incubation medium described previously (15). After this incubation, the membrane was rinsed twice for 5 min each time with the same incubation medium without ${ }^{3} \mathrm{H}$-ouabain and then dried. For autoradiography, the membrane was exposed to Fuji X-ray film for 4 weeks at $-70^{\circ} \mathrm{C}$ (C-3 in Fig. 1),

\section{Chemicals}

${ }^{3} \mathrm{H}$-Ouabain was from New England Nuclear (Boston, MA, USA). Con A Sepharose, WGA Sepharose and bovine serum albumin were from Sigma (St. Louis, MO, USA), as were all the protease inhibitors used (pepstatin A, aprotinin, jodoacetamide, leupeptin, benzamidine and phenylmethylfluoride). The marker proteins were from Bio-Rad Laboratories (New York, NY, USA). Goat anti- mouse immunogold (RPN 423) and goat anti-rabbit immunoglobulin were from Amersham (Amersham, UK). The ABC kit was from Vector Laboratories (Burlingame, CA, USA).

\section{RESULTS}

Characteristics of the NORP and specificity of the MOAB raised against it

Figure 1 illustrates the results of the extraction of NORP from TTM-JSR complexes. Lane 1 in A represents the SDS-PAGE profile of the TTM-JSR complexes from which the protein was extracted, and lane 2 shows the Con A-sensitive proteins isolated by Con A affinity chromatography. Lane 1 in $B$ represents WGA-sensitive proteins from TTM-JSR complexes (nonreducing conditions), while lane 2 represents Con A-sensitive proteins (nonreducing conditions) in the WGA-void fraction of TTM-JSR complexes. Lane 1 in $C$ represents the SDSPAGE profile of the purified $31.5-\mathrm{kD}$ protein from band $a$ in B-2. Lanes 2 and 3 in $C$ represent nitrocellulose transfers of lane 1. Lane 1 represents silver-stained NORP, lane 2 shows the Western blot profile used to determine the specificity of the MoAB against NORP and lane 3

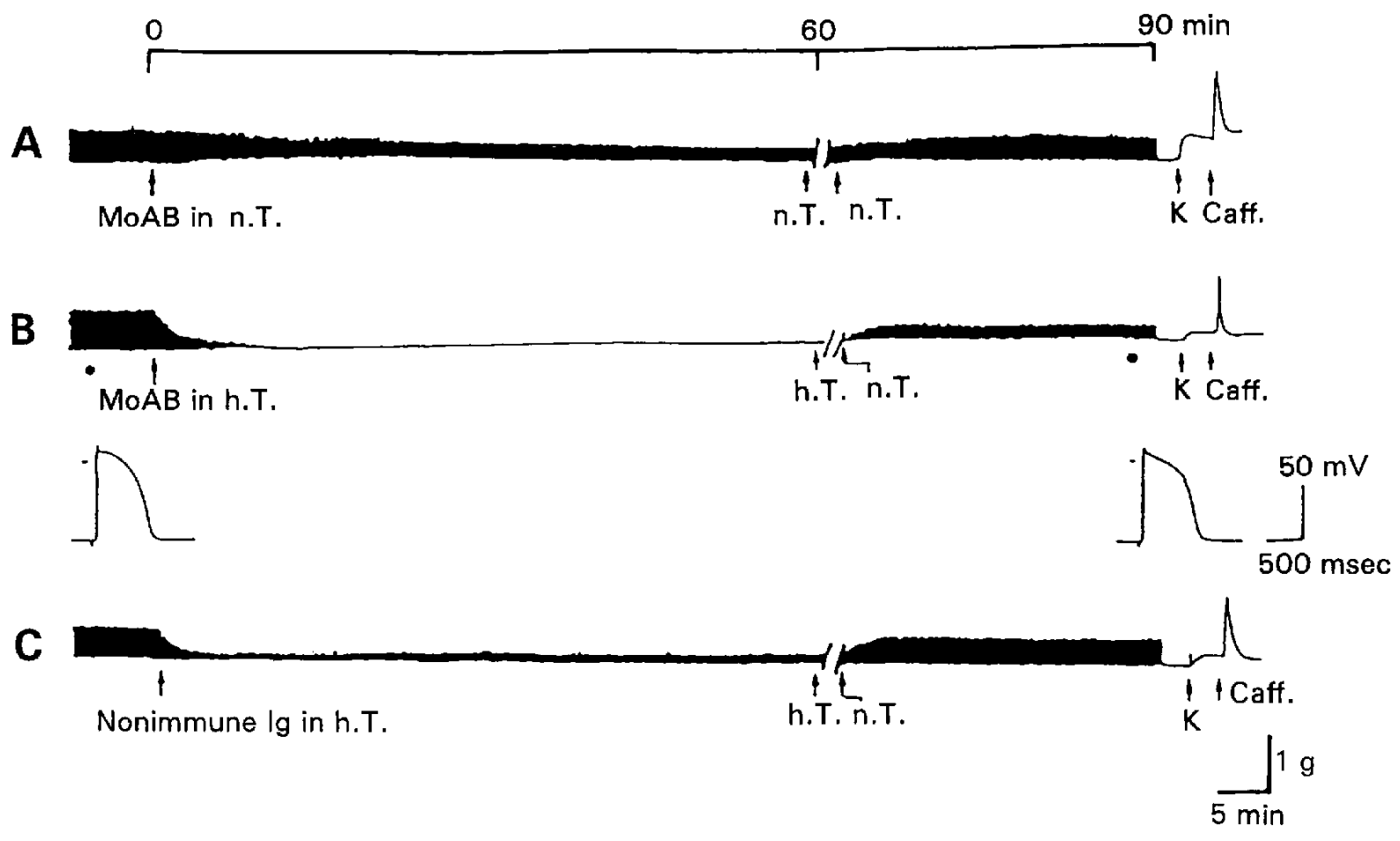

Fig. 2. Mechanograms showing the effects of the anti-NORP MoAB on the E-C coupling of kitten cardiac papillary muscles. A: MoAB application in normal Tyrode solution. B: MoAB application in Tyrode solution containing $200 \mathrm{mM} \mathrm{NaCl}$. C: nonimmune immunoglobulin application in $200 \mathrm{mM} \mathrm{NaCl}$ Tyrode solution. Symbols: $n$.T., substitution of normal Tyrode solution; h.T., substitution of Tyrode solution containing $200 \mathrm{mM} \mathrm{NaCl} ; \mathrm{K}$, substitution of K-Tyrode solution; Caff., substitution of KTyrode solution containing $50 \mathrm{mM}$ caffeine; nonimmune Ig, nonimmune immunoglobulin. For further explanations, see text. 
Table 1. Effects of the MOAB on membrane potentials

\begin{tabular}{ccc}
\hline & \multicolumn{2}{c}{ MoAB administration } \\
& before & after \\
\hline Action potential & & \\
amplitude (mV) & $106.24 \pm 7.40$ & $107.02 \pm 5.40$ \\
duration (msec) & $669.50 \pm 40.02$ & $635.22 \pm 61.00$ \\
\hline Resting potential (mV) & $81.10 \pm 7.30$ & $82.53 \pm 2.40$ \\
\hline
\end{tabular}

Potentials were recorded intracellularly during the course of the experiment on mechanical responses in the same tissues. The first (before application of $\mathrm{MOAB}$ ) and the second (after the application and just before the contracture-observations) symbols ( $\bullet$ ) in Fig. 2B indicate time points of the electrical observatons. Each value indicates a mean \pm S.E. $(N=5)$. There were no significant differences in resting and action potentials between before and after MoAB administration.

represents the autoradiogram after incubation with ${ }^{3} \mathrm{H}$ ouabain. From these data: 1) NORP shows high affinity for Con A but not for WGA, which has high affinity for the various subunits $\left(\alpha_{1}, \alpha_{2}, \beta, \gamma\right.$ and $\left.\delta\right)$ of the DHP-receptor protein $(38,41-43) ; 2)$ the MoAB prepared shows high specificity for NORP; and 3) NORP shows high ouabainbinding ability.

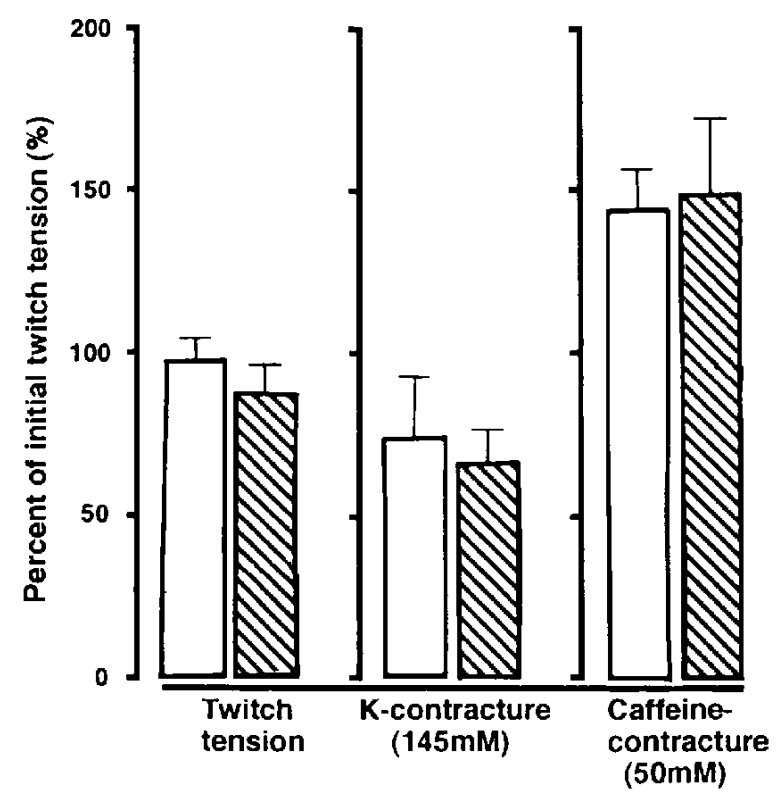

Fig. 3. Summary of contractile responses obtained through the procedure in mechanogram A of Fig. 2. Three kinds of mechanical responses at about $30 \mathrm{~min}$ after removal of MoAB were examined. Columns (open, with nonimmune immunoglobulin; hatched, with MoAB) show the mean \pm S.E. $(N=5)$ of peak tension of each response.
Effects of the anti-NORP MOAB on contractile responses

Figure 2 shows typical mechanograms obtained from kitten papillary muscles. In $\mathrm{B}$, the muscle was first immersed for $60 \mathrm{~min}$ in a slightly hypertonic Tyrode solution containing the anti NORP MoAB $(10 \mu \mathrm{g} / \mathrm{ml}, 2$-fold higher than the minimum concentration required for saturation), after which time the normal Tyrode solution was restored. The slightly hypertonic bathing solution was used to increase the accessibility of the MoAB to the TTM by dilating the tubules (37). As is seen in the mechanogram, about $30 \mathrm{~min}$ after removal of the $\mathrm{MoAB}$, both twitch and $\mathrm{K}$-contracture tensions decreased markedly without affecting caffeine-induced contracture and resting and action potentials (Table 1). In Fig. 2C, the procedure was the same as in $\mathrm{B}$ except for the use of nonimmune immunoglobulin instead of the anti-NORP MOAB, and no effects of the immunoglobulin were apparent on contractile responses $30 \mathrm{~min}$ after restoration of normal Tyrode solution. Comparison (Fig. 4) of contractile responses at this time point between mechanogram $B$ and $C$ shows clearly that the inhibition of contractile responses in $B$ is due to an action of the anti-NORP MoAB itself, indicating that it is the E-C coupling mechanism that is affected by MoAB, since the inhibition occurs without effects on resting and action potentials and caffeine-induced contracture. In A of Fig. 2 (see also Fig. 3), where the tissue was incubated with the anti-NORP MoAB (in control, non-

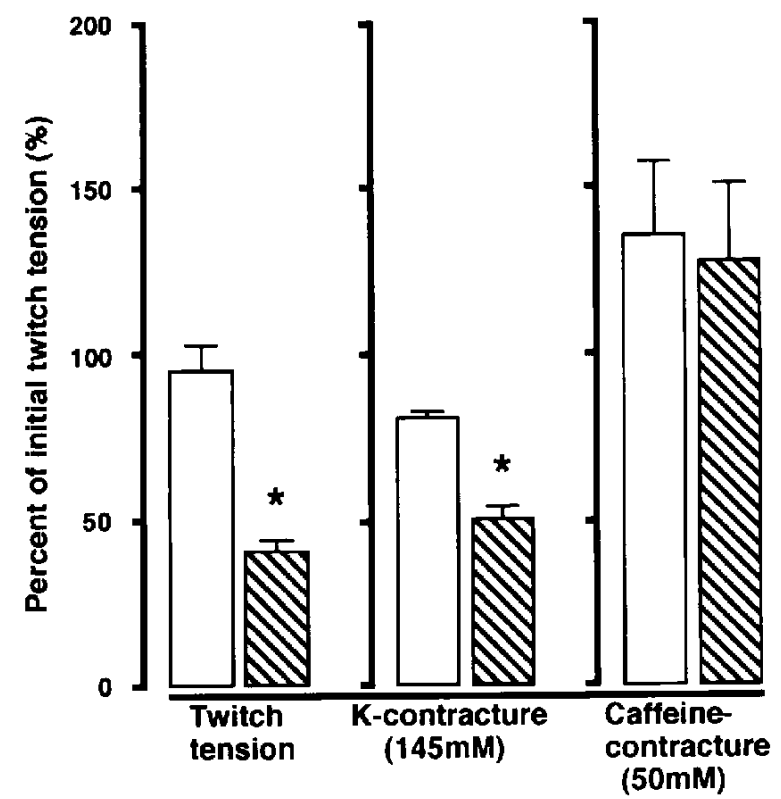

Fig. 4. Summary of contractile responses obtained through the procedure in mechanograms B and C of Fig. 2. Columns (open, with nonimmune immunoglobulin; hatched, with MoAB) show the mean \pm S.E. $(N=5)$ of peak tension of each contractile response. ${ }^{*} \mathrm{P}<0.001$, compared with nonimmune immunoglobulin. For other explanations, see Fig. 3. 
immune immunoglobulin was used) in isotonic Tyrode solution, no significant effect was observed on the E-C coupling process $30 \mathrm{~min}$ after removal of the MoAB. In mechanogram $\mathrm{A}$, there appeared to have been a small reduction in twitch magnitude during the 60 -min incubation with the MoAB under isotonic conditions, but this was statistically not significant.

Immunogold images in ultrathin sections of papillary muscle treated with the anti-NORP MOAB

Figure 5A shows an electron micrograph of a longitudinal section of cat non-conditioned papillary muscle dou-
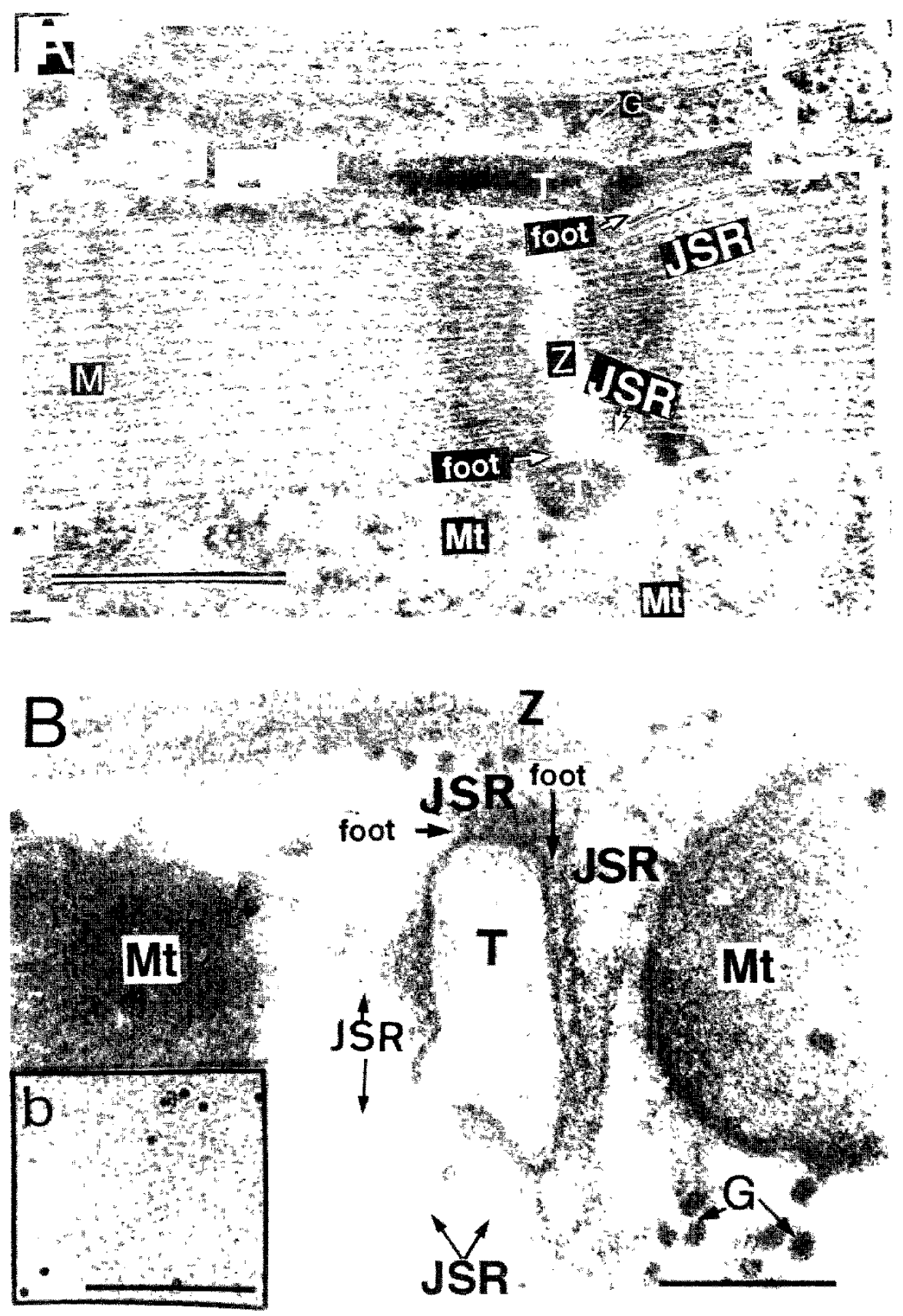

Fig. 5. Electron micrographic standard images of longitudınal sections in papillary muscle obtained from cat heart. A: Nonconditioned muscle. T, transverse tubule; JSR, junctional sarcoplasmic reticulum; Mt, mitochondrial; Z, Z-line; M, M-lıne; G, glycogen granules. Fixation with glutaraldehyde and $\mathrm{OsO}_{4}$ and double staining with lead citrate and uranyl acetate. Calibration, $0.5 \mathrm{rm}$. B: Muscle treated with nonimmune immunoglobulin (i.e., control of Fig. 6; cf. both C in Fig. 2 and open columns in Fig. 4). Standard fixation and double stannng of shorter times (each $4 \mathrm{~min}$ ) than usual. Calibration, $0.25 \mu \mathrm{m}$; abbreviations, the same as in A. b: the insertıon with calıbration of $0.25: \mathrm{m}$, immunogold particles on the collodion mesh. 

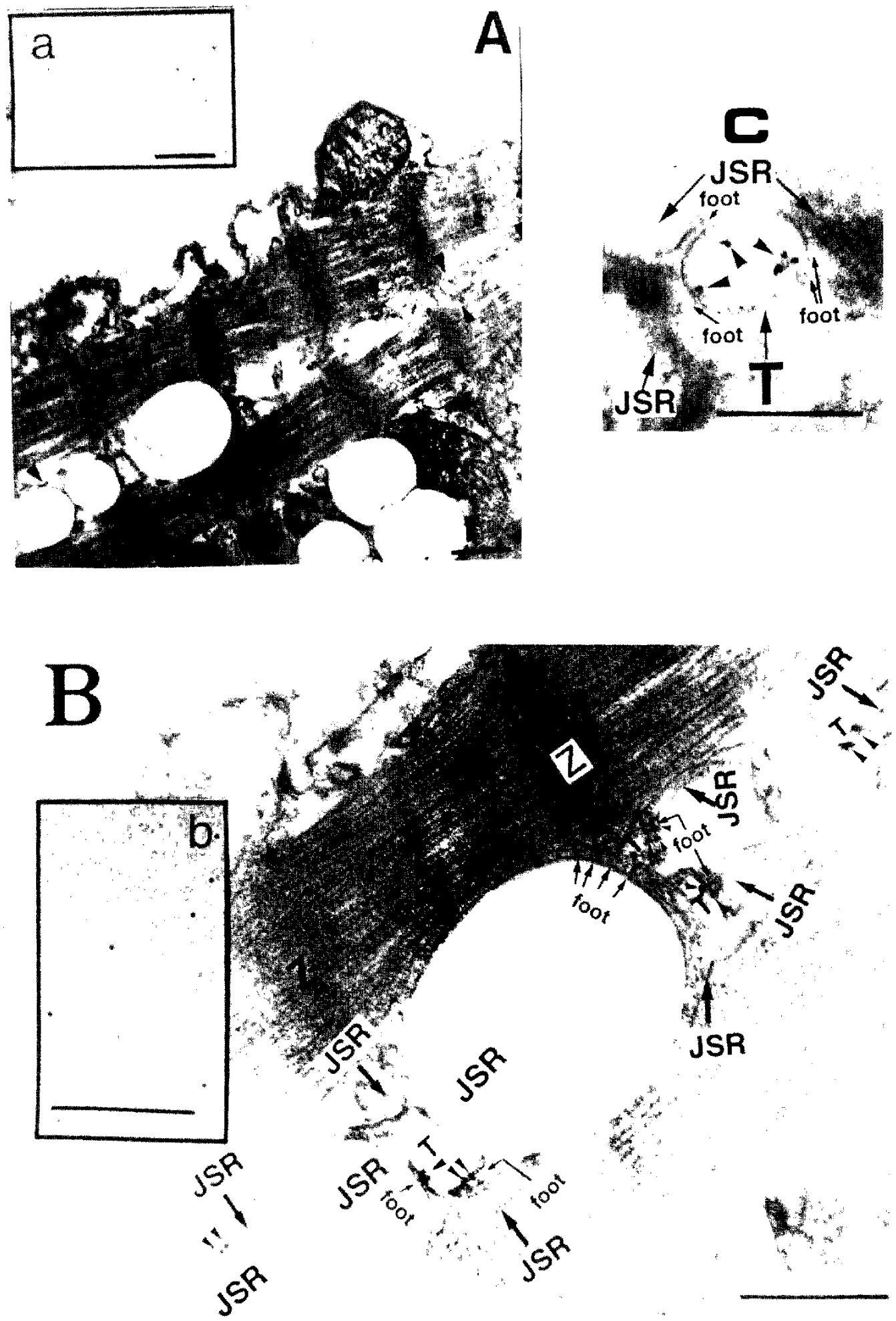

Fig. 6. Immunohistochemical (immunogold method) electron micrographs of longitudinal sections of cat papillary muscle. The tissue was treated with anti-NORP MOAB (cf. B in Fig. 2 and hatched columns in Fig. 4). Standard fixation and no staining. Arrowheads indicate immunogold particles. Abbreviations and calibrations are the same as in Fig. 5A. Lower (A) and higher (B) magnification of the same section; and $\mathrm{C}$ belongs to another section. $\mathrm{a}$ and $\mathrm{b}$ : immunogold particles on the collodion mesh. Notice the existence more than a few electron-dense particles (immunogold) on TTM or near the external surface of TTM, in spite of the absence of the particles anywhere in the control section shown in Fig. 5B. 
bly stained with uranyl acetate and lead citrate. In the vicinity of the $Z$ band, there exist diads, the functional and morphological units (19), of which junctional gaps between the TTM and JSR are connected by feet. Figure 5B shows a control section in which nonimmune immunoglobulin was applied instead of the anti-NORP MoAB (for the procedure, see Fig. $2 \mathrm{C}$ and Materials and Methods). The JSR vesicles showed a tendency to swell compared to the tissue shown in Fig. 5A. In these control sections, practically no immunogold particles were seen.

Figure 6 shows the immunolocalization of NORP in the anti-NORP MoAB-treated papillary muscle using the immunogold method (for detailed procedures, see Materials and Methods). One noticeable point in this figure is that there are considerable number of immunogold particles, which are hardly observable in Fig. 5B, which was obtained through the use of nonimmune immunoglobulin instead of anti-NORP MoAB. The JSR vesicles showed a tendency to swell, especially those in the hull-portion of the muscle, probably due to the hypertonic Tyгode solution used for application of the anti-NORP MoAB. These immunogold particles are recognizable in the TT-SR junctional regions located on the $\mathrm{Z}$ band-line level. The gold particles are visible mainly in the TTM-regions near the $Z$ band which were often accompanied by feet. The gold particles were not always present on the external surface of the TTM, although their location would be expected to have a close relation to the TTM-surface. This is probably due to both the possible bending of the longitudinal TTaxis within the cut section and the relationship between marker particles of constitutional complexity and the protein to be detected, NORP.

In Fig. 7, A and B show typical immunohistochemical electron micrographs obtained by the ABC method, and $C$ is a control section using nonimmune immunoglobulin (cf. the afore-mentioned description in Fig. 5B). In C, almost no special electron-dense spots are seen; In contrast, in $\mathrm{A}$ and $\mathrm{B}$, electron-dense spots are visible that are in close relation to the TTM opposite the feet (i.e., in B, at the external surface of TTM; in A, on the TTM). These results demonstrate that the electron-dense spots result from the antigen-antibody reaction between anti-NORP MoAB and NORP at the TTM; and therefore, they show that NORP or some portion of it is situated at the external surface of the TTM opposite the feet.

\section{DISCUSSION}

The present study of NORP was based on the following observations and deductions reported in our previous study (15): 1) The molecular weight of NORP was found to be $31.5 \mathrm{kD}$ by SDS-PAGE, and it was demonstrated to be localized solely in the TTM-JSR system, a structural
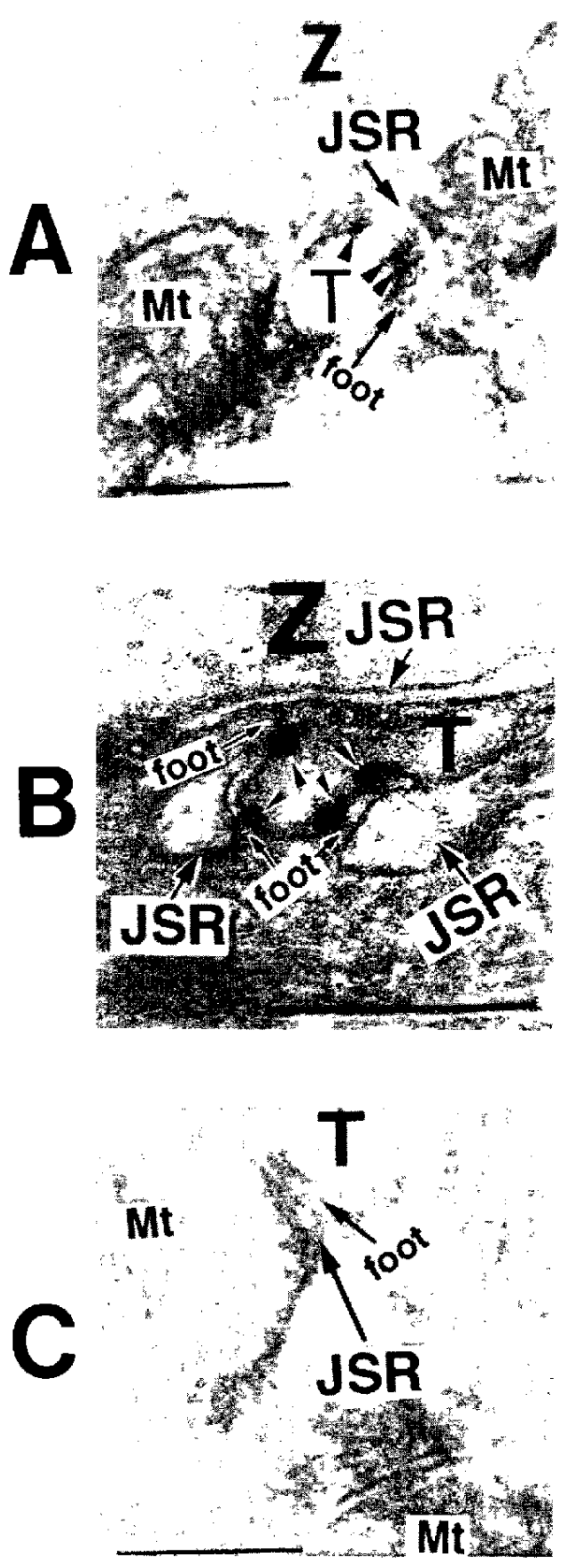

Fig. 7. Immunohistochemical ( $A B C$ method) electron micrographs of longitudinal sections of cat papillary muscle. A and B (with MoAB) and $C$ (with nonimmune immunoglobulin, i.e., control) were obtained from sections without double staining. Arrowheads indicate electron-dense spots produced by the $\mathrm{ABC}$ method. Abbreviations and calibration are the same as in Fig. 5A. Notice the existence of electron-dense spots on TTM or at the external surface of TTM opposite the feet in A and B (especially in B), in spite of the absence of the spots in $\mathrm{C}$ (control).

system dedicated to the E-C coupling mechanism; 2) NORP shows a high binding affinity for ouabain, and it binds to the drug even at very low concentrations, which are just sufficient to induce the PIE. Therefore, NORP 
should play a key role in PIE and must be considered in discussions on the mechanism of the PIE of ouabain. Thus, the present study expands our previous findings by applying affinity chromatography and immunological techniques using anti-NORP MoAB (37).

Figures $1 \mathrm{~A}$ and $1 \mathrm{~B}$ show that NORP, the $31.5-\mathrm{kD}$ protein, is a Con A-sensitive glycoprotein, extractable selectively and effectively from TTM-JSR complexes by Con A affinity chromatography, confirming point 1 above. Fig. $1 \mathrm{C}$ shows that NORP is ouabain-sensitive and binds to ouabain at $0.5 \mu \mathrm{M}$, consistent with point 2 above. Fig. $1 \mathrm{~B}$ is significant not only for its confirmation of our previous findings (15), but also for allowing deductions of the physiological role of NORP. A sufficient quantity of Con Asensitive $31.5-\mathrm{kD}$ protein was extracted from the WGAvoid fraction. This indicates that NORP is WGA-insensitive but Con A-sensitive. It follows that NORP is unrelated to WGA-sensitive proteins such as DHP-receptor protein, including the subunits, which are the glycoproteins of $30-32 \mathrm{kD}(38,41-43)$. Therefore, the physiological role of NORP in myocardial cells probably differs from that of the DHP-receptor and its related proteins.

The present investigation with the anti-NORP MoAB has raised several notable points (Figs. 1, 4, 6 and 7) with respect to the physiological role and the localization of NORP. As described in the Results section, the protein prepared by means of the immunochemical procedures in the present study is undoubtedly the MoAB against NORP (Fig. 1C), and the minimum saturation value calculated from the ELISA-result for the binding of the MoAB to purified NORP was $5 \times 10^{-6} \mu \mathrm{g} / \mathrm{ml}$ (about 40 $\mathrm{nM})$. Therefore, $1 \times 10^{-5} \mu \mathrm{g} / \mathrm{ml}$ of the MoAB, i.e., twice the minimum saturation value, were used throughout the immunochemical and immunohistological procedures. Thus, since the anti-NORP MoAB showed high specificity, our findings are indicative of the following physiological and pharmacological roles of NORP.

As shown in Figs. 2-4, the anti-NORP MoAB, applied extracellularly, functionally inhibited E-C coupling in cardiac muscle cells. Since the MoAB is a large molecule, NORP must be located at a membrane-site that is exposed, whether partially or completely, to the extracellular environment. This is compatible with the observation that the MoAB does not influence caffeine-induced contracture that appears to be mediated through an intracellular action of the drug. According to the experiments presented in Figs. 6 (the immunogold method) and 7A and $-\mathrm{B}$ (the $\mathrm{ABC}$ method), which were undertaken to identify immunomorphologically the site of ouabain attack, the NORP as the ouabain-site appears to be located at sites of the TTM opposite the feet, a ryanodine receptor composed of 4 subunits (44-46), spanning the gap between the TTM and JSR. As described in the Results sec- tion, we investigated the localization of the NORP antigen during the course of the evident MoAB-induced inhibition of E-C coupling in living myocardial cells. Therefore, it follows that extracellular NORP at TTM forms a morphological unit for $\mathrm{E}-\mathrm{C}$ coupling with the feet and junctional SR (i.e., the NORP-feet-JSR unit) and functions as the input-apparatus for E-C coupling. Thus, since NORP is the most ouabain-sensitive component in the TTM-JSR system (15), these immunological observations suggest a sound morphological explanation of why ouabain-PIE proceeds via E-C coupling. The detailed mechanisms by which NORP serves as the input-apparatus for E-C coupling and binding of the MoAB to NORP inhibits E-C coupling remain to be determined, but it seems likely that both are closely related.

How NORP mediates the PIE of ouabain is at present not clear. However, it is interesting to note that proteins homologous to NORP, namely, 31.5-kD Con A-sensitive and WGA-insensitive proteins, have been extracted from TTM-JSR of not only cat cardiac muscle but also muscle tissues from several other species $(25,36,37,47,48)$. Of these, that from frog skeletal muscle $(37,47-49)$ has been investigated in detail and is composed of a head and tail, the former of which has been shown to move mechanically $(37,47-49)$. Thus, the name "electrometrin" has been suggested for this protein, as its head portion is considered to move mechanically measuring the membrane potentials in a way similar to the indicator of an electrometer and appears, therefore, to behave as an electromechanic transducer $(48,49)$. Indeed, the $31.5-\mathrm{kD}$ Con Asensitive and WGA-insensitive proteins from TTM-JSR of various muscle tissues from the various species studied are likely to belong to the electrometrin family; however, immunological investigations have indicated that the MoAB raised against cat cardiac NORP shows a $10 \%$ crossreaction to frog skeletal electrometrin, and a MoAB raised against frog skeletal electrometrin shows a $50 \%$ crossreaction to rabbit skeletal electrometrin, indicating that the new protein, electrometrin, is differentiated to various degrees depending on the functional specificity of tissues (49). It seems probable that this differentiation has some pharmacological significance.

In conclusion, the present study suggests that E-C coupling in cardiac muscle cells is mediated by input via NORP and that ouabain-PIE takes place through the influence of the drug on NORP in the E-C coupling process.

\section{Acknowledgments}

This work was supported by a Grant-in-Aid for Scientific Research from the Ministry of Education, Science and Culture of Japan (No. 62590090). 


\section{REFERENCES}

1 Lee KS and Klaus W: The subcellular basis for the mechanism of inotropic action of cardiac glycosides. Pharmacol Rev 23, $193-261$ (1971)

2 Okita GT, Richardson F and Roth-Schechter BF: Dissociation of the positive inotropic action of digitalis from inhibition of sodium and potassium-activated adenosine triphosphatase. J Pharmacol Exp Ther 185, 1- 11 (1973)

3 McDonald TF, Nawrath $H$ and Trautwein W: Membrane currents and tension in cat ventricular muscle treated with cardiac glycosides. Circ Res 37, 674-682 (1975)

4 Akera $\mathrm{T}$ and Brody TM: The role of $\left(\mathrm{Na}^{+}-\mathrm{K}^{+}\right)$-ATPase in the inotropic action. Pharmacol Rev 29, 185-247 (1977)

5 Godfraind $\mathrm{T}$ and Ghysel-Burton J: Binding sites related to ouabain induced stimulation or inhibition of the sodium pump. Nature 265, 165-166 (1977)

6 Erdmann E, Philipp G and Scholz H: Cardiac glycoside receptor, $\left(\mathrm{Na}^{-}-\mathrm{K}^{+}\right)$-ATPase activity and force of contraction in rat heart. Biochem Pharmacol 29, 3219-3229 (1980)

7 Adams RJ, Schwartz A, Grupp IL, Lee SW, Wallic ET, Powell T, Twist W and Gathiram P: High affinity ouabain binding site and low-dose positive inotropic effect at myocardium. Nature 296, 167-169 (1982)

8 Isenberg G: Cardiac Glycoside Receptors and Positive Inotropy, Edited by Erdmann E, p 56, Steinkopf, Darmstadt (1984)

9 Allen DG and Blinks JR: Calcium transients in aequorin-injected frog cardiac muscle. Nature 237, 509-519 (1978)

10 Allen DG, Eisner DA and Wray SC: Birthday present for digitalis. Nature 316, 674-675 (1985)

11 Rasmussen HH, Robert E, Okita GT, Hertz RS and Siner DH: Inhibition of electrogenic Na-pumping attributable binding of cardiac steroids to high-affinity pump sites in human atrium. J Pharmacol Exp Ther 235, 629-635 (1985)

12 Kim D, Crayoe EJ Jr and Smith TW: Relations activities, and Ca-H interaction in cultured chick heart cells. Circ Res 60 , $185-193$ (1987)

13 Schwartz A, Grupp G, Wallick EA, Grupp IL and Ball WJ: Role of $\mathrm{Na}^{-}, \mathrm{K}^{+}$-ATPase in the cardiotonic action of cardiac glycosides. Prog Clin Biol Res 268B, 321 - 338 (1988)

14 Heller M: Cardiac glycosides (new/old ideas about old drugs). Biochem Pharmacol 40, 919-925 (1990)

15 Fujino S, Sato K, Bando T, Kurokawa T, Nakai T, Takashima $\mathrm{K}$ and Fujino $\mathrm{M}$; Solubilization and characterization of a ouabain-sensitive protein from transverse tubule membrane-junctional sarcoplasmic reticulum complexes (TTM-JSR) in cat cardiac muscle. Experientia 45, 466-469 (1989)

16 Beuckelmann DJ and Wier WG: Mechanism of release of calcium from sarcoplasmic reticulum of guinea pig cardiac cells. J Physiol (Lond) 405, 233-255 (1988)

17 Ebashi S: Excitation-contraction coupling. Annu Rev Physiol 38, 293-313 (1976)

18 Endo M: Calcium release from sarcoplasmic reticulum. Physiol Rev 57, 71-108 (1977)

19 Fabiato $\mathrm{A}$ and Fabiato F: Calcium and cardiac excitation-contraction coupling. Annu Rev Physiol 41, 473-484 (1979)

20 Fujino M, Yamaguchi T and Suzuki K: "Glycerol effect" and the mechanism linking excitation of the plasma membrane with contraction. Nature 192, 1159-1161 (1961)
21 Fujino M, Yamaguchi T and Fujino S: 'Glycerol effect' in various kinds of muscle cell. Jpn J Physiol 22, 477-489 (1972)

22 Ashley CC and Ridgway EB: On the relationship between membrane potential, calcium transit and tension in single barnacle muscle fibers. J Physiol (Lond) 209, $105-130$ (1970)

23 Rios E and Brum G: Involvement of dihydropyridine receptors, in excitation-contraction coupling in skeletal muscle. Nature 325, 717-720 (1987)

24 Etter EF: The effect of phenylglyxal on contraction and intramembrane charge movement in frog skeletal muscle. I Physiol (Lond) 421, 441-462 (1990)

25 Fujino M, Arima T, Hasegawa $C$, Harano $\mathrm{K}$, Takahashi $M$, Sano $S$ and Fujino S: The surface input site responsible for excitation mechanism in single skeletal muscle fibres of frog. Adv Exp Med Biol 311, 431 - 432 (1992)

26 Fujino S, Izumi T, Kawagishi S and Tanaka M: Availability of cardiac glycosides for pharmacological receptor-site of muscle cells and positive inotropic action. Jpn J Pharmacol 19, $170-171$ (1969)

27 Fujino S, Tanaka M and Fujino M: Microinjection of ouabain into crab muscle fibers. Nature 223, 413-414 (1969)

28 Fujino S, Kawagishi N, Eguchi $\mathrm{N}$ and Tanaka M: Binding site of ouabain in cardiac muscle cell and its positive inotropic effect in cat. Jpn J Pharmacol 21, 423-425 (1971)

29 Fujino S: Positive inotropic action evoked by intracellular effects of ouabain in heart ventricle of frog. Proc Jpn Acad 50, 226-230 (1974)

30 Fujino S: The mechanism of action of cardiac glycosides. Jpn J Pharmacol 26, Supp 7P (1976)

31 Fujino S, Igarashi $\mathrm{T}$ and Hoshi $\mathrm{K}$ : Ouabain potentiation of $\mathrm{Ca}$ release from cardiac sarcoplasmic reticulum fragments. Jpn J Pharmacol 29, 839-845 (1979)

32 Fujino S, Igarashi T, Hoshi $\mathrm{K}$ and Fujino M: Ouabain potentiation of $\mathrm{Ca}$ release from cardiac sarcoplasmic reticulum fragments isolated from cat hearts. Experientia 35, 1220-1221 (1979)

33 Fujino S and Fujino M: Microinjection of ouabain into crab single muscle fibers and the mechanism of ouabain potentiation. Can J Physiol Pharmacol 58, 712-722 (1980)

34 Fujino $S$ and Fujino M: Ouabain potentiation of rapid cooling contracture of caffeinized cardiac muscles in calcium deprived medium. Jpn J Pharmacol 30, 711-720 (1980)

35 Fujino S and Fujino M: Ouabain potentiation and Ca release from sarcoplasmic and skeletal muscle cells. Can J Physiol Pharmacol 60, 542-555 (1982)

36 Fujino M, Fujino S, Satoh K, Nakai T and Kado T: Physiological role and localization of new ouabain receptor protein $\mathbf{3 1 . 5}$ $\mathrm{kD}$ ) from cat cardiac muscles, using the monoclonal $\mathrm{AB}$ against the protein. Adv Exp Med Biol 311, 449-451 (1992)

37 Fujino S, Sato K, Nakai T, Togashi K, Kado T, Fujino M, Arima $T$ and Fujino M: Studies of a key protein in the mechanism of the excitation-contraction coupling process of frog skeletal muscle, using phenylglyoxal. Experientia 49, 138-144 (1993)

38 Curtis BM and Catterall WA: Purification of the calcium antagonist receptor of the voltage-sensitive calcium channel from skeletal transverse tubules. Biochemistry 23, 2113-2118 (1985)

39 Laemmli UK: Cleavage of structural proteins during the assembly of the head of bacteriophage-T4. Nature 227, 680-685 (1970)

40 Towbin HM, Staehelin TM and Gorgen J: Electrophoretic trans- 
fer of protein from polyacrylamide gels to nitrocellulose sheets: procedure and some applications. Proc Natl Acad Sci USA 76, 4350-4354 (1979)

41 Leung AT, Imagawa $T$, Block B, Franzini-Armstrong $C$ and Cempbell KP: Biochemical and ultrastructural characterization of 1,4-dihydropyridine receptor from rabbit skeletal muscle. J Biol Chem 262, 7943 - 7946 (1988)

42 Tanabe T, Beam KB, Powerll JA and Numa S: Restoration of excitation-contraction coupling and slow calcium current in dysgenic muscle by dihydropyridine receptor complementary DNA. Nature 336, 134-139 (1988)

43 Tanabe T, Mikami A, Numa S and Beam KG: Cardiac-type excitation-contraction coupling in dysgenic skeletal muscle injected with cardiac dihydropyridine receptor cDNA. Nature 344, $451-453$ (1990)

44 Kawamoto RM, Bruschwig J-P, Kim KC and Caswell AH: Isolation, characterization, and localization of the spanning protein from skeletal muscle triads. J Cell Biol 103, 1405-1414 (1986)

45 Block BA, Imagawa T, Campbell KP and Flanzini-Armstrong
C: Structural evidence for direct interaction between the molecular components of the transverse tubule-sarcoplasmic reticulum junction in skeletal muscle. J Cell Biol 107, 2587-2600 (1988)

46 Lai FA, Erickson HP, Rousseau E, Liu QY and Meissner G: Purification and reconstitution of the calcium release channel from skeletal muscle. Nature 331, 315-319 (1988)

47 Fujino S, Fujino M, Sato K, Nakai T, Kado T, Arima T and Fujino M: Solubilization, physiological role and localization of a key protein $(31.5 \mathrm{kD})$ to excitation-contraction coupling process of frog skeletal muscle cells, using phenylglyoxal. Ady Exp Med Biol 311, 339-340 (1992)

48 Arima T, Fujino M, Hasegawa C, Harano K, Satoh K, Fujino $M$, Nakai $T$ and Fujino S: Electromechanical transductions and a new substance responsible for functioning of input mechanism for E-C coupling. J Physiol Soc Jpn 54, 395-415 (1992)

49 Fujino M, Fujino S, Miura K, Sato K and Nakai T: Characteristics of electrometrin solubilized from striated muscles. Abstracts of XXXII Congress of the Int Union of Physiol Sci, Glasgow, 116.4/O, p 129 (1993) 